\title{
Thermoplastic Cassava Starch-PVA Composite Films with Cellulose Nanofibers from Oil Palm Empty Fruit Bunches as Reinforcement Agent
}

\author{
Farah Fahma, Sugiarto, Titi Candra Sunarti, \\ Sabrina Manora Indriyani, and Nurmalisa Lisdayana \\ Department of Agroindustrial Technology, Faculty of Agricultural Engineering and Technology, Bogor Agricultural University, \\ Bogor, Indonesia \\ Correspondence should be addressed to Farah Fahma; farah_fahma@yahoo.com
}

Received 2 April 2017; Revised 11 August 2017; Accepted 16 August 2017; Published 20 September 2017

Academic Editor: Antje Potthast

Copyright (C) 2017 Farah Fahma et al. This is an open access article distributed under the Creative Commons Attribution License, which permits unrestricted use, distribution, and reproduction in any medium, provided the original work is properly cited.

\begin{abstract}
Thermoplastic starch-polyvinyl alcohol composite films were prepared by casting method with cellulose nanofibers as reinforcement agent and glycerol as plasticizer. The obtained cellulose nanofibers with a diameter of $27.23 \pm 8.21 \mathrm{~nm}$ were isolated from oil palm empty fruit bunches (OPEFBs) by mechanical treatment. The addition of cellulose nanofibers until 3 wt $\%$ increased tensile strength and crystallinity of the composite films. In contrast, it decreased their elongation at break and water vapor transmission rate. Meanwhile, the addition of glycerol increased elongation at break and water vapor transmission rate of film matrix but lowers tensile strength of composite films.
\end{abstract}

\section{Introduction}

Petroleum-based packaging has caused serious environmental problems because it does not decompose easily in nature. In recent years, many studies on new bio-based materials for food packaging have been done in order to replace their nondegradable counterparts. Because of its low cost, biodegradability, and availability, starch is one of the most natural polymers attractively studied for application of food packaging. Starch is widely available in nature and a promising raw material for making biodegradable plastics. Starch is renewable, rapidly degraded in environment, and nontoxic [1]. Starch consists of amylose and amylopectin. Amylose is a linear polymer consisting of $\alpha$-(1,4)-D-glucopyranose, while amylopectin is a highly branched macromolecule composed of both $\alpha$-(1,4) and $\alpha$-(1,6) glucopyranosyl linkages [2].

Thermoplastic starch (TPS) is produced through destruction of starch granular using shear forces at high temperature in presence of plasticizer. This process happens by breaking hydrogen bonds between the starch macromolecules, coinciding with a partial depolymerization of starch backbone [3]. In food packaging application TPS films have drawbacks, that is, poor mechanical performance and high moisture absorption. Two approaches to overcome these disadvantages are addition of reinforcement agent and blending with other polymers.

Polymer blending is an important method to produce new materials that can meet with our needs. Polyvinyl alcohol (PVA) is a synthetic polymer which can be degraded naturally. PVA is also widely used in packaging industry because it is tasteless, odorless, nontoxic, dissolvable in water, and resistant to oil and fat. PVA has hydroxyl groups ($\mathrm{OH}$ ) in its structure which tends to form the intermolecular and intramolecular hydrogen bonds thereby increasing the integrity of mixture of TPS-PVA. It also has good capability for film forming [4].

Cellulose is a major component of plant and has played an important role in maintaining structure of plant cell walls. Cellulose is a linear homopolymer of $\beta$-D-glucopyranose units joined by $(1 \rightarrow 4)$ glycosidic linkages $[5,6]$. Cellulose nanofibers obtained from different treatment and different sources showed different properties [7-9]. We have succeeded to isolate cellulose nanofibers from OPEFBs by acid hydrolysis [5]. The addition of cellulose nanofibers as 
reinforcement agent into TPS production has been studied by some researchers. Thermoplastic cassava starch was reinforced with cassava baggase cellulose nanofibrils [10]. Cellulose microfibrils from potato tuber cell waxy starch cellulose nanocrystals were also added to TPS films [2, 11]. All results showed that the addition of cellulose nanofibers increases the mechanical performance of TPS films.

In food packaging, vapor and gas permeability and migration of certain components are important issues [12]. Oxygen and water vapor can deteriorate food properties, so that the barriers to them are critical properties to consider in packaging materials. The hard diffusivity influences the gas diffusion through the film $[2,12]$.

In 2014 Indonesia produced around 29.24 million tons of crude palm oil (CPO) [13]. Each year, Indonesia produces a lot of OPEFBs as a byproduct of the palm oil industry. Therefore the use of OPEFBs as a nanosized reinforcement agent in the composite production is one alternative to improve the added value of OPEFBs.

This study is concerned with the production of TPS/PVA composite films with addition of cellulose nanofibers from OPEFBs as reinforcing agent and glycerol as plasticizer. In this study, cellulose nanofibers from OPEFBs were isolated by mechanical treatment using modification of ultrafine-grinder and ultrasonification. The effect of cellulose nanofibers content and glycerol on the properties of TPS/PVA matrix was evaluated by some analyses.

\section{Materials and Methods}

2.1. Materials. Native cassava starch (Alini brand) with $99.5 \%$ purity was purchased from market. OPEFBs for obtaining nanofibers were supplied by PTPN VIII, Kertajaya, Lebak, West Java, Indonesia. Glycerol (commercial grade product), PVA (produced by Celvol ${ }^{\mathrm{TM}}$ Sekisui Chemical Co. ltd), potassium hydroxide $(\mathrm{KOH})$, and sodium hypochlorite $(\mathrm{NaOCl})$ were used as received without any further purification.

\subsection{Preparation of Cellulose Fibers from OPEFBs. Dry} OPEFBs were cut to approximately $1 \mathrm{~cm}$ length and boiled with water at $100^{\circ} \mathrm{C}$ for 1 hour to remove impurities. Then, $50 \mathrm{~g}$ of cut OPEFBs were immersed in $1000 \mathrm{~mL}$ solution of $\mathrm{KOH} 6 \%$ for 12 hours at a room temperature and subsequently washed to neutral $\mathrm{pH}$. Bleaching was done by soaking OPEFBs in $12 \%$ of hypochlorite solution for 5 hours at room temperature. The obtained cellulose pulp was then washed to a neutral $\mathrm{pH}$ and stored in a refrigerator prior to preparation of cellulose nanofibers.

2.3. Preparation of Cellulose Nanofibers from OPEFBs. The cellulose pulp was dispersed in water using a warring blender. Subsequently, the concentration of the pulp suspension was adjusted to $1-2 \%$ by adding water. The suspension was then passed 37 times through ultrafine-grinder (Masuko Co., Ltd) at $1500 \mathrm{rpm}$. Hereinafter the suspension was done with ultrasonification at $40 \%$ of amplitude for 30 minutes.
2.4. Preparation of TPS-PVA Nanocomposite Films. TPS-PVA composite films with addition of cellulose nanofibers were prepared by solution casting method. Cassava starch and PVA were mixed with the comparison of $4: 1$ and dissolved in water. The mixing was performed with stirring and heating up to $90^{\circ} \mathrm{C}$ for 10 minutes. In this step, the gelatinization of granular starch occurred. The suspension was added with glycerol as plasticizer ( 0 and $25 \mathrm{wt} \%$ ) and cellulose nanofibers $(0,1,3$, and $5 \mathrm{wt} \%)$ and then stirred for 15 minutes. Subsequently, the material was molded in Teflon mold and dried in oven at $45^{\circ} \mathrm{C}$ for 48 hours. A series of TPS/PVA cellulose nanocomposite was coded as SPG-aNF-b, where SP stands for starch and PVA, G for glycerol, a for the percentage of glycerol, NF for nanofibers, and $b$ for the percentage of nanofibers content.

2.5. Scanning Electron Microscopy (SEM) Observation. The morphology of obtained cellulose nanofibers was observed by SEM (SEM Zeiss EVOMA 10) operating at $16 \mathrm{kV}$. Thirty nanofibers for each sample in the SEM images were randomly selected and measured using ImageJ software. The average diameters of nanofibers were calculated.

2.6. Water Vapor Transmission Rate (WVTR). The WVTR was determined by the gravimetric with the modification method of ASTM E96 [14]. The nanocomposite film was cut to the size of $20 \mathrm{~mm} \times 20 \mathrm{~mm}$ and conditioned in a desiccator for 24 hours. Then the film was laid on the surface of small container containing anhydrous $\mathrm{CaCl}_{2}$. The sample was weighed and stored in the desiccator containing saturated $\mathrm{KCl}$. The test was carried out at room temperature and $\mathrm{RH}$ in the desiccator of $70 \%$. The WVTR was calculated by the following formula:

$$
\mathrm{WVTR}=\frac{\Delta m / \Delta t}{A}
$$

where WVTR is the water vapor transmission rate ( $\mathrm{g} / \mathrm{m}^{2} /$ hour), $\Delta m$ is the difference in mass of the container (mg), $\Delta t$ is the difference in time, and $A$ is area $\left(\mathrm{m}^{2}\right)$.

2.7. X-Ray Diffraction. The test of X-ray diffraction (XRD) was performed using a XRD Bruker D8 with a radiation of $\mathrm{K} \alpha \mathrm{Cu}(\lambda=1.54060)$. The sample with a diameter of $5 \mathrm{~cm}$ was placed on the sample holder and the analysis was performed on the operating conditions of $40 \mathrm{kV}$ and $35 \mathrm{~mA}$.

2.8. Mechanical Properties. The tensile tests were performed using universal testing machine (Instron). The nanocomposite film with a size of $45 \mathrm{~mm} \times 20 \mathrm{~mm} \times 40-50 \mu \mathrm{m}$ was clamped between the grips. Three measurements were conducted to characterize each sample at a crosshead speed of $3 \mathrm{~mm} / \mathrm{min}$.

\section{Results and Discussion}

3.1. Morphology of Cellulose Nanofibers from OPEFBs. Based on the analysis, the contents of cellulose, hemicellulose, and 


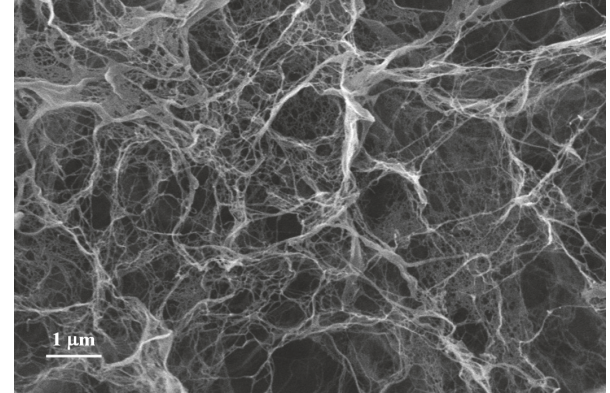

FIGURE 1: SEM image of cellulose nanofibers from OPEFBs isolated by mechanical treatment.

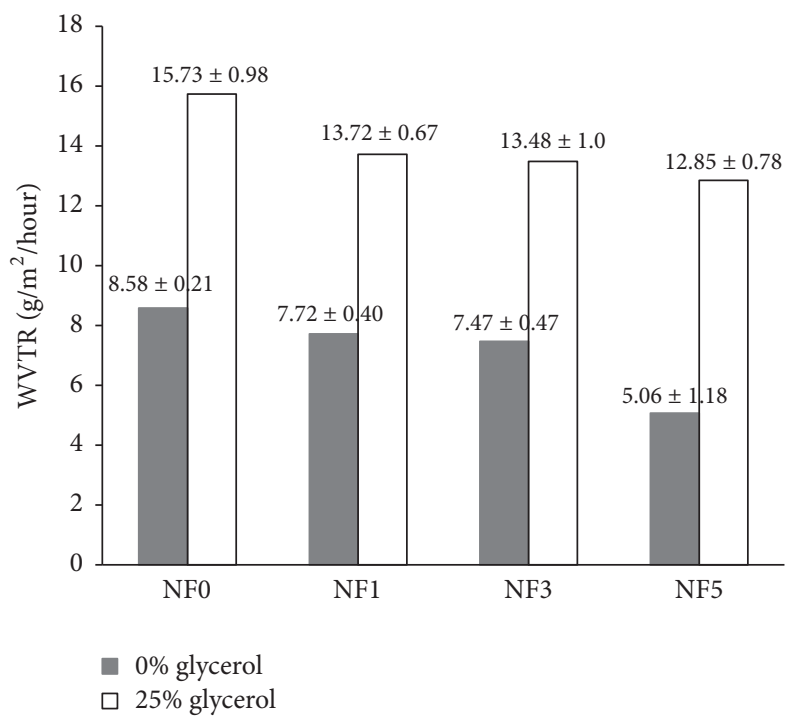

FIGURE 2: Water vapor transmission rate of TPS-PVA cellulose nanocomposite films.

lignin of OPEFBs used in this study were $52.28 \%, 20.7 \%$, and $27.02 \%$, respectively. After bleaching and alkali treatment for preparing cellulose fibers, the chemical contents of pulp were $76.53 \%$ of cellulose, $17.66 \%$ of hemicellulose, and $5.81 \%$ of lignin. The lignin content was lower compared to the lignin content in OPEFBs. It showed that the delignification and bleaching processes succeeded in reducing the lignin and hemicellulose significantly. The cellulose fibers obtained were reduced in size mechanically to nanoscale using combination of ultrafine-grinder and ultrasonicator. Figure 1 shows the SEM image of the cellulose nanofibers produced. The cellulose nanofibers produced from OPEFBs have the diameter of $27.23 \pm 8.21 \mathrm{~nm}$.

\subsection{Characterization of TPS-PVA Nanocomposite Films}

3.2.1. Water Vapor Transmission Rate (WVTR). The WVTR of TPS-PVA cellulose nanocomposite films can be seen in Figure 2. The addition of cellulose nanofibers lowers the WVTR. It might be caused by the cellulose nanofibers which made the changing of the lanes of the direct diffusion of
TABLE 1: Crystallinity of TPS/PVA cellulose nanocomposite films.

\begin{tabular}{lc}
\hline Sample & Crystallinity \\
\hline SPG0NF0 & 26.3 \\
SPG0NF1 & 28.2 \\
SPG0NF3 & 32.7 \\
SPG0NF5 & 37.8 \\
SPG25NF0 & 21.8 \\
SPG25NF1 & 27.8 \\
SPG25NF3 & 30.5 \\
SPG25NF5 & 35.3 \\
\hline
\end{tabular}

the water molecule into the composite become tortuous (tortuous path); thus they blocked the water vapor to pass through the film [15]. The film without the addition of the glycerol shows that the WVTR is lower compared to the film with the glycerol. The glycerol is hydrophilic that can improve the hygroscopic properties so that it has the ability to absorb the water from air around the material and to increase the WVTR of the material.

3.2.2. X-Ray Diffraction (XRD). The X-ray diffraction profiles and crystallinity of nanocomposite films can be seen in Figure 3 and Table 1, respectively. The film without the addition of glycerol has a higher degree of the crystallinity compared with the film using glycerol. Chen et al. [16] reported that PVA exhibited an obvious diffraction peak at $19.4^{\circ}$. In Figures 3(a) and 3(b), all peaks in tapioca starch were not observed and all diffraction patterns seem very close to that of PVA; even in a nanocomposite film, starch content was four times more than the PVA. This might be because of the destruction of crystalline structure of starch granules caused by the gelatinization during the mixing process with PVA at $90^{\circ} \mathrm{C}$ for 10 minutes.

Both Figures 3(a) and 3(b) exhibit that increasing cellulose nanofibers content made differential peak at $22.5^{\circ}$ more obvious gradually. Meanwhile, the addition of glycerol gave the changed diffraction pattern of nanocomposites. It means that the crystalline structure of nanocomposites strongly was influenced by PVA, glycerol molecules, and cellulose nanofibers.

The final crystallinity of materials depends on the ability of the chain to form crystals, as well as on the mobility of the chain. With glycerol content the crystallinity of starch films decreases due to the decrease of intra- and intermolecular interactions of the starch-starch chain [17]. Meanwhile, with increasing cellulose nanofibers, the crystallinity of TPS-PVA composite films increased.

According to Savadekar et al. [18], the existing crystallinity in the cellulose nanofibers also helps improve the crystallinity of the TPS-PVA nanocomposite films. The higher percentage of crystallinity of the nanocomposite film makes the film stronger, because of the compact and orderly structure. This affects the tensile strength of the composite film. 


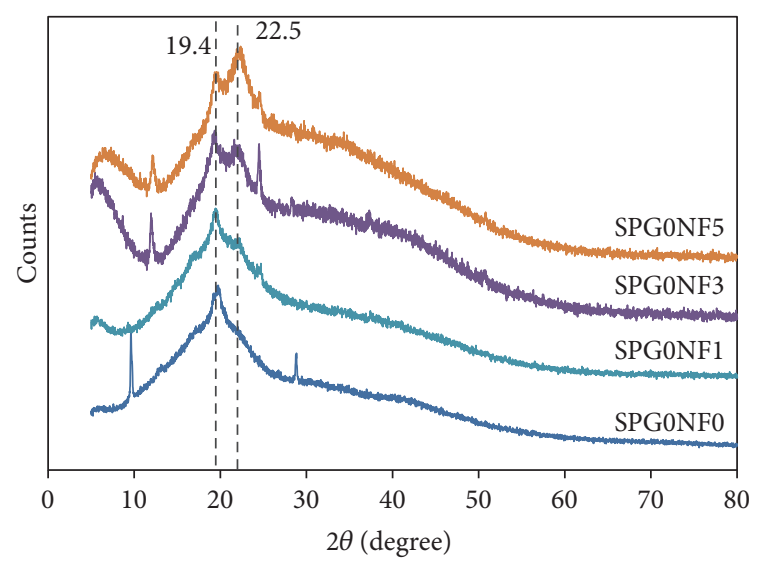

(a)

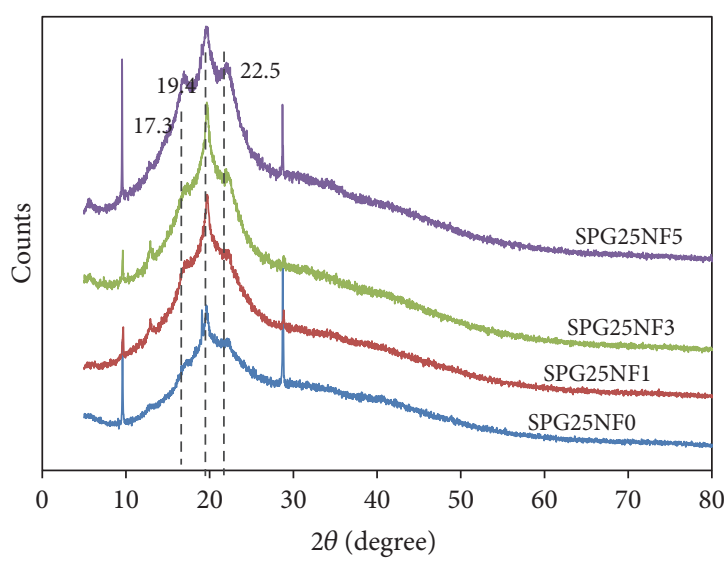

(b)

FIGURE 3: XRD Profiles of TPS/PVA cellulose nanocomposite films (a) without glycerol; (b) with glycerol.

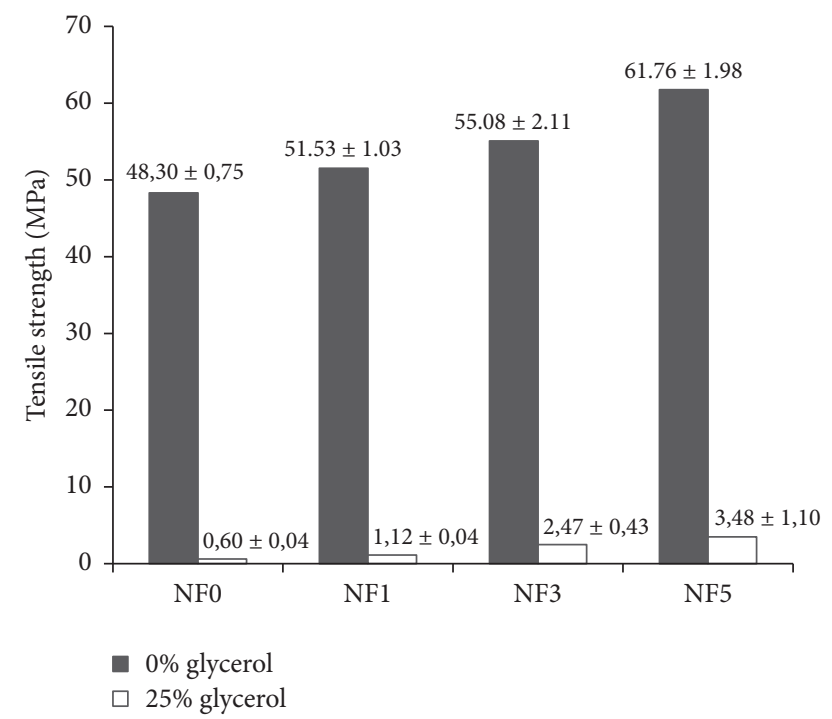

Figure 4: Tensile strength of TPS/PVA cellulose nanocomposite films.

3.2.3. Mechanical Properties. The tensile strength of TPS/ PVA cellulose nanocomposite films can be seen in Figure 4 . The tensile strength of neat TPS/PVA film was $48.3 \mathrm{MPa}$. Obviously, the addition of cellulose nanofibers improved tensile strength of TPS/PVA films. With increasing cellulose nanofibers content up to 5\%, tensile strength of TPS/PVA films without glycerol improved $28 \%$ from $48.30 \mathrm{MPa}$ to $61.76 \mathrm{MPa}$. Both matrix TPS/PVA and cellulose nanofibers as filler have identical chemical nature, that is, hydroxyl groups. Therefore, a good affinity between them could happen, causing the formation of strong hydrogen bonded percolation cellulose nanofibers network at their interfaces and giving reinforcement effect. The increase of tensile strength due to the addition of cellulose nanofibers indicates that interfacial adhesion between TPS/PVA as polymer matrix and cellulose nanofibers occurred.

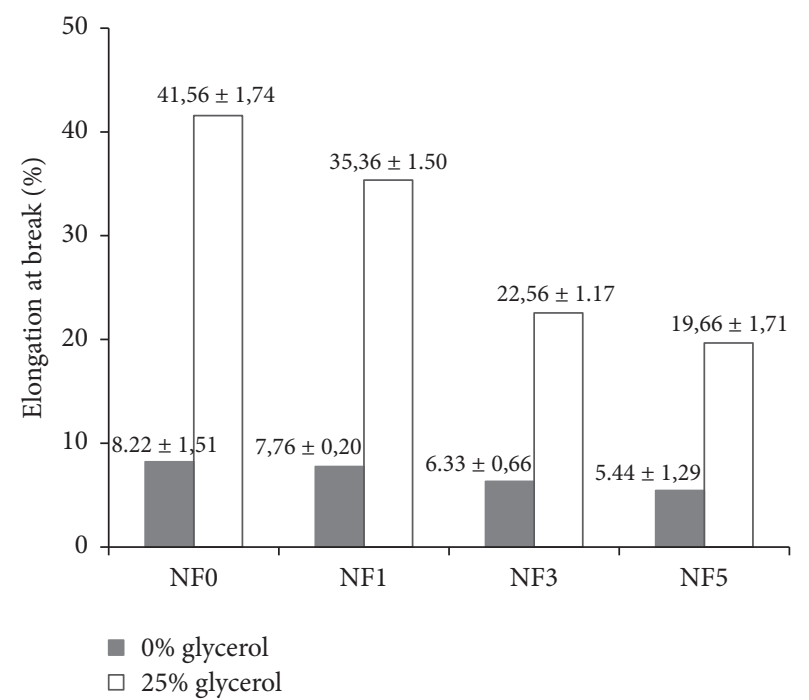

FIGURE 5: Elongation at break of TPS/PVA cellulose nanocomposite films.

Figure 4 exhibits that there is a difference in the tensile strength between nanocomposite films with glycerol and the films without glycerol. Glycerol reduces the inter- and intramolecular forces of the polysaccharide chain so that the film structure becomes more flexible [19]. The addition of glycerol caused tensile strength to decrease significantly. These results were supported by the results of X-ray diffraction analysis.

Figure 5 shows that with increasing cellulose nanofibers content the elongation at break decreased. The film without the addition of glycerol has the lower elongation value compared to the film with the addition of glycerol. The presence of the plasticizer in TPS can interrupt the formation of double helices from the amylose with the branch of amylopectin; then it reduces the interaction between the molecules of amylose and amylopectin; thereby it increases the flexibility of film [20]. 


\section{Conclusion}

The isolation of the cellulose nanofiber from OPEFBs succeeded mechanically with the size of $27.23 \pm 8.21 \mathrm{~nm}$. The cellulose nanofibers showed good reinforcement in the nanocomposite films of TPS-PVA. The addition of the cellulose nanofibers lowered the WVTR, but the addition of glycerol increased the WVTR of the composite films. The film without glycerol had the better tensile strength, but it lowered the elongation at break of the film and made the film not elastic. The addition of cellulose nanofibers also lowered the elongation at break of the film. The film crystallinity was more increasing with increasing cellulose nanofibers content. The film with glycerol had the lower crystallinity compared to the film without glycerol.

\section{Conflicts of Interest}

The authors declare that they have no conflicts of interest.

\section{Acknowledgments}

Financial support from Kemenristekdikti with HIKOM scheme (Contract no. 079/SP2H/LT/DRPM/II/2016 on 17 February 2016) is gratefully acknowledged. The authors also would like to thank Bogor Agricultural University (Program Hibah Mobititas Dosen dan Hibah Penulisan manuskrip untuk Publikasi Internasional).

\section{References}

[1] S. Kampangkaew, C. Thongpin, and O. Santawtee, "The synthesis of cellulose nanofibers from Sesbania Javanica for filler in thermoplastic starch," Energy Procedia, vol. 56, pp. 318-325, 2014.

[2] K. González, A. Retegi, A. González, A. Eceiza, and N. Gabilondo, "Starch and cellulose nanocrystals together into thermoplastic starch bionanocomposites," Carbohydrate Polymers, vol. 117, pp. 83-90, 2015.

[3] J. Ren, H. Fu, T. Ren, and W. Yuan, "Preparation, characterization and properties of binary and ternary blends with thermoplastic starch, poly(lactic acid) and poly(butylene adipate-coterephthalate)," Carbohydrate Polymers, vol. 77, no. 3, pp. 576$582,2009$.

[4] Z. Liu, Y. Dong, H. Men, M. Jiang, J. Tong, and J. Zhou, "Postcrosslinking modification of thermoplastic starch/PVA blend films by using sodium hexametaphosphate," Carbohydrate Polymers, vol. 89, no. 2, pp. 473-477, 2012.

[5] F. Fahma, S. Iwamoto, N. Hori, T. Iwata, and A. Takemura, "Isolation, preparation, and characterization of nanofibers from oil palm empty-fruit-bunch (OPEFB)," Cellulose, vol. 17, no. 5, pp. 977-985, 2010.

[6] S. Kalia, A. Dufresne, B. M. Cherian et al., "Cellulose-based bioand nanocomposites: a review," International Journal of Polymer Science, vol. 2011, Article ID 837875, 35 pages, 2011.

[7] F. Fahma, S. Iwamoto, N. Hori, T. Iwata, and A. Takemura, "Effect of pre-acid-hydrolysis treatment on morphology and properties of cellulose nanowhiskers from coconut husk," Cellulose, vol. 18, no. 2, pp. 443-450, 2011.
[8] F. Fahma, N. Hori, S. Iwamoto, T. Iwata, and A. Takemura, "Cellulose nanowhiskers from sugar palm fibers," Emirates Journal of Food and Agriculture, vol. 28, no. 8, pp. 566-571, 2016.

[9] K. Wahyuningsih, E. S. Iriani, and F. Fahma, "Utilization of cellulose from pineapple leaf fibers as nanofiller in polyvinyl alcohol-based film," Indonesian Journal of Chemistry, vol. 16, no. 2, pp. 181-189, 2016.

[10] E. D. M. Teixeira, D. Pasquini, A. A. S. Curvelo, E. Corradini, M. N. Belgacem, and A. Dufresne, "Cassava bagasse cellulose nanofibrils reinforced thermoplastic cassava starch," Carbohydrate Polymers, vol. 78, no. 3, pp. 422-431, 2009.

[11] B. Montero, M. Rico, S. Rodríguez-Llamazares, L. Barral, and R. Bouza, "Effect of nanocellulose as a filler on biodegradable thermoplastic starch films from tuber, cereal and legume," Carbohydrate Polymers, vol. 157, pp. 1094-1104, 2017.

[12] T. V. Duncan, "Applications of nanotechnology in food packaging and food safety: barrier materials, antimicrobials and sensors," Journal of Colloid and Interface Science, vol. 363, no. 1, pp. 1-24, 2011.

[13] Badan Pusat Statistik, "Produksi Perkebunan Besar menurut Jenis Tanaman, Indonesia 1995-2014 and Produksi Perkebunan Rakyat Menurut Jenis Tanaman 2000-2014," 2016, https://www .bps.go.id/linkTabelStatis/view/id/1666.

[14] America Society for Testing Materials, Standard Test Methods for Water Vapor Transmission Rate of Materials (E96), America Society for Testing Materials, Washington, DC, USA, 1995.

[15] N. S. Lani, Ngadi N., A. Johari, and M. Jusoh, "Isolation, characterization, and application of nanocellulose from oil palm empty fruit bunch fiber as nanocomposites," Journal of Nanomaterials, vol. 2014, Article ID 702538, 9 pages, 2014.

[16] Y. Chen, X. Cao, P. R. Chang, and M. A. Huneault, "Comparative study on the films of poly(vinyl alcohol)/pea starch nanocrystals and poly(vinyl alcohol)/native pea starch," Carbohydrate Polymers, vol. 73, no. 1, pp. 8-17, 2008.

[17] V. P. Cyras, M. C. T. Zenklusen, and A. Vazquez, "Relationship between structure and properties of modified potato starch biodegradable films," Journal of Applied Polymer Science, vol. 101, no. 6, pp. 4313-4319, 2006.

[18] N. R. Savadekar, V. S. Karande, N. Vigneshwaran, A. K. Bharimalla, and S. T. Mhaske, "Preparation of nano cellulose fibers and its application in kappa-carrageenan based film," International Journal of Biological Macromolecules, vol. 51, no. 5, pp. 1008-1013, 2012.

[19] N. Cao, Y. Fu, and J. He, "Preparation and physical properties of soy protein isolate and gelatin composite films," Food Hydrocolloids, vol. 21, no. 7, pp. 1153-1162, 2007.

[20] Y. Zhang and J. H. Han, "Plasticization of pea starch films with monosaccharides and polyols," Journal of Food Science, vol. 71, no. 6, pp. E253-E261, 2006. 

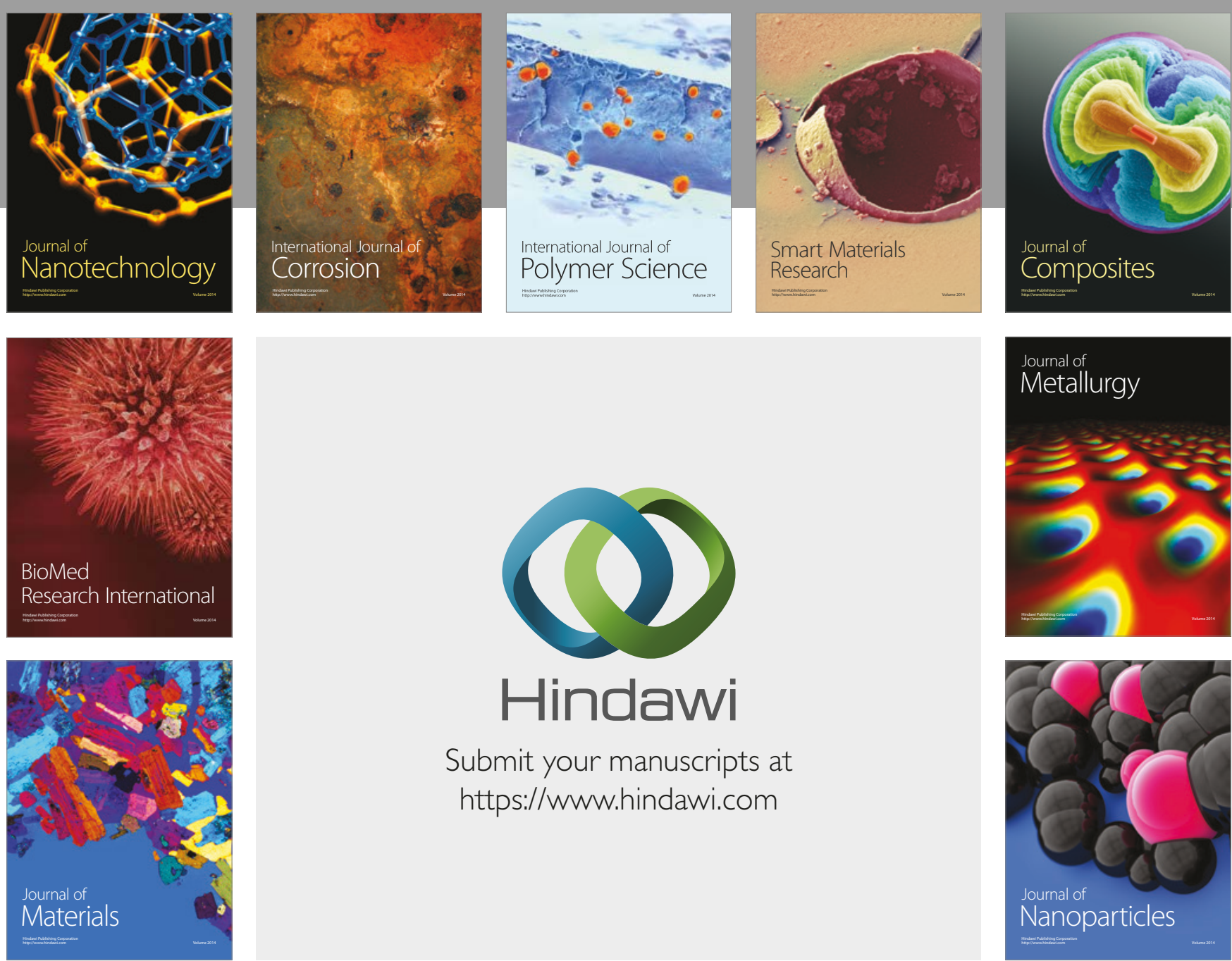

\section{Hindawi}

Submit your manuscripts at

https://www.hindawi.com
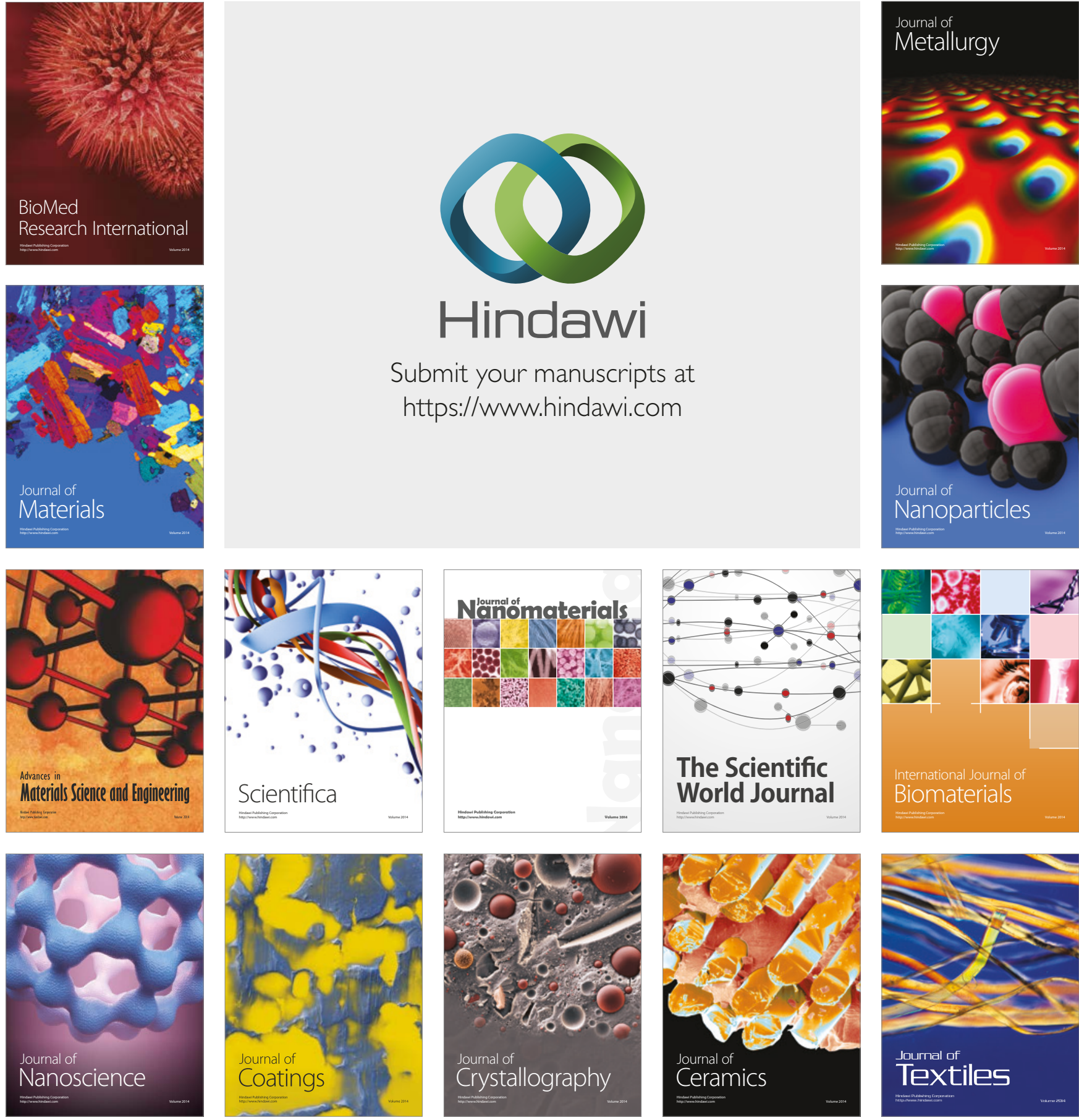

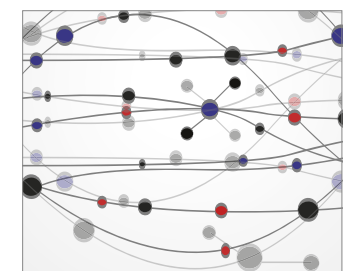

The Scientific World Journal
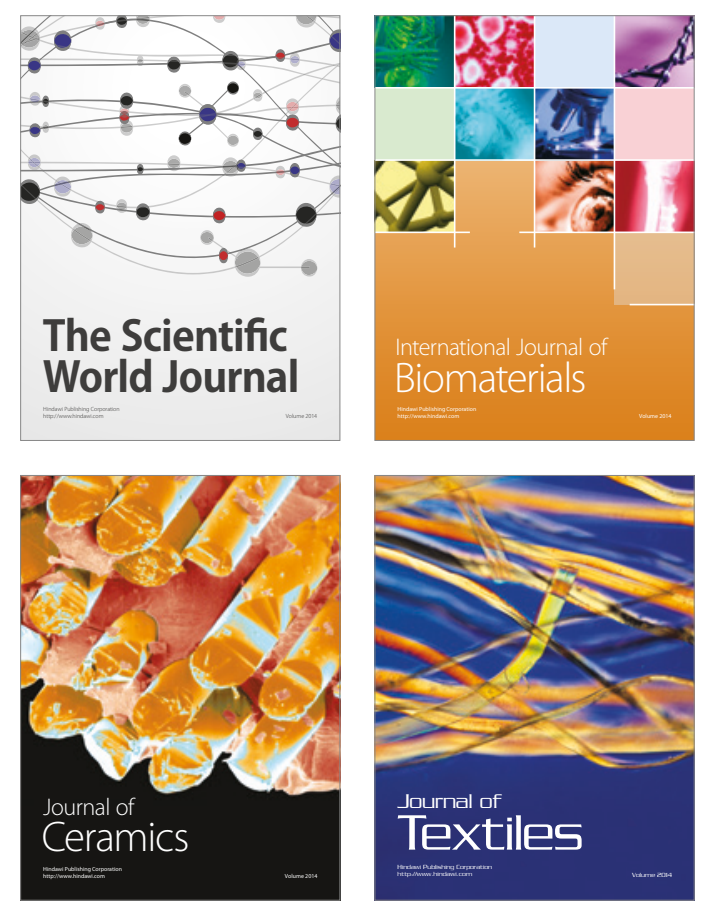